\title{
An Approach to Predict Debris Flow Average Velocity
}

\author{
Chen Cao ${ }^{1}$, Shengyuan Song ${ }^{1}$, Jianping Chen ${ }^{1, *}$, Lianjing Zheng ${ }^{2}$ and Yuanyuan Kong ${ }^{1}$ \\ 1 College of Construction Engineering of Jilin University, Changchun 130026, Jilin, China; \\ caochen14@mails.jlu.edu.cn (C.C.); songshengyuan@jlu.edu.cn (S.S.); kongyy14@126.com (Y.K.) \\ 2 Changchun Sci-Tech University, Changchun 130600, Jilin, China; zhengljcc@gmail.com \\ * Correspondence: chenjp@jlu.edu.cn; Tel.: +86-431-8850-2353
}

Academic Editor: Karl-Erich Lindenschmidt

Received: 3 November 2016; Accepted: 8 March 2017; Published: 10 March 2017

\begin{abstract}
Debris flow is one of the major threats for the sustainability of environmental and social development. The velocity directly determines the impact on the vulnerability. This study focuses on an approach using radial basis function (RBF) neural network and gravitational search algorithm (GSA) for predicting debris flow velocity. A total of 50 debris flow events were investigated in the Jiangjia gully. These data were used for building the GSA-based RBF approach (GSA-RBF). Eighty percent (40 groups) of the measured data were selected randomly as the training database. The other $20 \%$ (10 groups) of data were used as testing data. Finally, the approach was applied to predict six debris flow gullies velocities in the Wudongde Dam site area, where environmental conditions were similar to the Jiangiia gully. The modified Dongchuan empirical equation and the pulled particle analysis of debris flow (PPA) approach were used for comparison and validation. The results showed that: (i) the GSA-RBF predicted debris flow velocity values are very close to the measured values, which performs better than those using RBF neural network alone; (ii) the GSA-RBF results and the MDEE results are similar in the Jiangjia gully debris flow velocities prediction, and GSA-RBF performs better; (iii) in the study area, the GSA-RBF results are validated reliable; and (iv) we could consider more variables in predicting the debris flow velocity by using GSA-RBF on the basis of measured data in other areas, which is more applicable. Because the GSA-RBF approach was more accurate, both the numerical simulation and the empirical equation can be taken into consideration for constructing debris flow mitigation works. They could be complementary and verified for each other.
\end{abstract}

Keywords: gravitational search algorithm; radial basis function; debris flow velocity; prediction approach

\section{Introduction}

Debris flow is a common geological disaster in mountain regions [1]. It is a type of sudden, ferocious and destructive natural disaster [2-6]. Prediction of debris flow is always an important task in geological hazards prevention works. The debris flow usually brings a great number of casualties and widespread damages [7]. The average velocity is an important parameter for designing mitigation structures [8,9]. The discharge, the run-out distance, the energy, the impact force, and the inundated area are all related to the average velocity. Thus, prediction of debris flow velocity is an important guidance to the construction of dams for sediment storage.

As debris flow moves as a whole; from a macroscopic viewpoint, it is possible to describe the motion by a single velocity, despite the variations within the flow body [6]. This single velocity can be considered as a characteristic quantity, which depends on the measurement. Johnson et al. [10] demonstrated that debris flow velocity was much higher at top surface than that in the bottom. In practice, the average velocity characterizes the overall movement of the fluid body is sufficient to assess a potential debris flow. Field monitoring is an effective approach for estimating debris-flow 
velocities. Common instruments include acoustic sensors [11], ultrasonic sensors [12] and fixed video cameras [13], and methods including spatial filtering [14] have been used to measure both surface velocity and average velocity. In the Jiangjia gully in China, two methods are used to measure debris flow velocity [6]. One method is timing the surge front position when passing through two fixed cross sections to measure the average velocity. People also use ultrasonic sensors to monitor the temporal fluctuation of velocity.

However, few gullies allow real-time monitoring of debris flow. Most debris flow gullies have no monitoring sites or instruments. The measured velocity data can be utilized for building approaches to calculate the average velocities. Nowadays, empirical formulations, back-calculation equations, and equations based on debris flow models, are the three categories of debris flow velocity equations [15]. Empirical formulation can be based on back-calculation (calibration of past events) or on geomorphological characteristics, while another category could be based on physic based formula taking into account the stress generated mechanisms acting during the debris flow propagation. Because of the distinctive features of debris flow, it is difficult to analyze debris flow motion $[16,17]$. Selection of appropriate influencing variables becomes very important in the data mining process. The debris flow velocity is mainly dominated by the following parameters: grain size, slope angle, sediment concentration, etc. [18-24]. Armanini et al. [18] conducted the laboratory experiments studying the rheological behavior of high-concentration granular-liquid mixtures. Hotta et al. [19] developed an experimental system employing a differential gas pressure gauge to measure the basal interstitial water pressure in shallow laboratory debris flows in an open channel. Iverson et al. [20] collected data of 28 controlled experiments to reveal that sediment mud content causes systematic differences in flow dynamics. Stancanelli [21] conducted a set of 19 experiments considering three values of the confluence angle, two slopes of the tributary, and three different triggering conditions. Stancanelli et al. [22] considered that within the investigated range of parameters, the slope angle was the parameter that mainly influences the stony debris flow mobility. As for the wide and shallow debris flow gully, the hydraulic radius can be replaced by flow depth. Yang [25] showed that average velocity of the viscous debris flow has a significant correlation with flow depth and channel slope. Yang also found that average velocity was influenced by the sediment properties represented by clay content and grain size non-uniformity. Prochaska [26] and Cagnoli [27] found that the velocity generally decreased with increasing grain size. Julien and Paris [28] employed the ratio of flow depth to median grain size, $\mathrm{h} / \mathrm{D}_{50}$. In China, the modified Dongchuan empirical equation [29] is specially used for calculating the debris flow velocity in the Dongchuan area, where the Jiangjia gully is located, as well as Koch's empirical velocity equation [30], both of which are based on the Manning equation [31]. Based on the pulled particle analysis (PPA), Huang [32] proposed an equation considering the research of the initial condition of solid accretion of debris flow to calculate the debris flow velocity. The pulled particle analysis approach is based on the theory of the solid-liquid two phase of debris flow, taking the solid particles of the moving debris flow as the analyzed object, establishing a limit equilibrium equation from the static to the motion state. Then, a new debris flow velocity approach is established. In such a framework, debris flow average velocity is obtained based on field monitoring through instruments or calculation equations. However, it can benefit from computer modeling. Debris flow is a complex and open system; the average velocity prediction approach implies that the use of meaningful variables gathered from past events is appropriate to predict the velocity. This study aims at building nonlinear relationships between the influencing variables and debris flow average velocity using data mining techniques. In the last few decades, artificial neural networks, typically radial basis function (RBF) neural network, have become efficient approaches to provide non-linear relations, especially in the multi component quantitative mixture from different types of data sets [33-35]. RBF neural network learning rule is simple and easy to be used on computer. It also has a strong robustness, memory and self-learning ability. Gravitational search algorithm (GSA) is one of common ways in optimizing the architecture, the centers and the width of RBF neural network. By combining the GSA with RBF neural network, a new hybrid algorithm (GSA-RBF) was proposed to predict debris flow average 
velocity. RBF neural network is sensitive to the initialization, and easy to fall into local optimum, but the new algorithm can avoid these disadvantages effectively. This study proposed a new approach, GSA-RBF neural network, to predict six gullies debris flow average velocity in the Wudongde Dam reservoir area. Xu et al. [36] and Wang et al. [37] have done precious works in this area. In particular, by training observation data of the Jiangjia gully, Xu et al. used BP neural network to establish an approach to predict three debris flow velocities in the Wudongde Dam reservoir area. They selected four variables to predict the velocity: flow depth, gradient of channel, debris flow density, and grain size. They compared the results with results computed by the Dongchuan equation and the modified Manning equation, finding that the BP approach is feasible and can predict the average velocity of a debris flow accurately. However, Poggio and Girosi [38] proved that RBF neural network was the best approximation for continuous functions, but BP was not. Yu [39] also proved that BP has poor prediction ability for testing data. The RBF has its disadvantages, i.e., it easily falls into the local optimal solution and leads the results to be not accurate. In this study, we selected the same variables as $\mathrm{Xu}$ et al. and tried to use the RBF neural network to train and predict the debris flow velocity. Meanwhile, GSA is used for optimizing the RBF neural network, which is necessary. In addition, Wang et al. evaluated the susceptibility of debris flows in the Wudongde Dam area using principle component analysis and self-organizing map methodologies. Twelve debris flow influencing factors are selected to evaluate the susceptibility of debris flows. The work of Wang et al. is referential, which will help to validate the results of our work.

\section{Study Area}

The study area lies along the lower reaches of the Jinsha River (Figure 1), and is the reservoir area of the Wudongde Dam site, which is located in the mountains separating Sichuan and Yunnan Provinces. It will be constructed as a massive hydropower station in the lower reaches of the Jinsha River. The riverbanks are steep, with an average gradient exceeding $45^{\circ}$. The study area is located in the central mountains and alpine region with $3600 \mathrm{~m}$ above sea level as the highest altitude. The altitude gradually increases from west to east of the study area. The section from the Wudongde Dam site to $14 \mathrm{~km}$ upstream is characterized by red bed soft rocks of the Triassic, Jurassic, and Cretaceous periods (T-K), including sandstones, shale, and mudstones. These rocks are easy to be physically weathered. The surface layers are completely weathered. The soil erosions and shallow landslides are widely distributed throughout the area.

The study area covers a dry-hot valley and has a low-latitude plateau subtropical monsoon climate. The climate is characterized by plentiful sunlight and large evaporation capacity, with concentrated rainfall and succession of wet and dry seasons. The study area is characterized by a subtropical monsoon climate. Different elevation exists, and various climatic zones exist due to the influence of the western subtropical monsoon and the particular geomorphic characteristics of high mountains and valleys. The maximum daily rainfall in the study area ranges between 834 and $1309 \mathrm{~mm}$. The heaviest rainfall occurs from May to October and peaks in July. The average annual temperature in the study area is $9-18{ }^{\circ} \mathrm{C}$. The vegetal cover is characterized by natural savanna and sparse broad-leaved woods. The vegetation in the study area covers less than $30 \%$.

The six debris flow gullies are located in the region of the Wudongde Dam site reservoir. The six gullies are selected based on the analysis of satellite images. They are Xiabaitan, Shangbaitan, Zhugongdi, Zhuzhahe, Zhiligou and Mengguogou. It is shown in Figure 1 that three gullies, Xiabaitan, Shangbaitan and Zhugongdi, are located near the dam site. The Wudongde dam area is rugged. It is difficult to transport construction facilities. Considering that there is limitation for construction place along Jinsha River, the three gullies will be used as a temporary ancillary facilities construction site. The debris flow channels in the area of the dam should be filled, and protection measures should be adopted [40]. Figure 2a shows the alluvial fan of Mengguogou catchment. Figure $2 \mathrm{~b}$ presents the farmland of Zhuzhahe catchment. Meanwhile, Figure 3 shows that there are some villages and 
farmlands near the alluvial fan in the entrance of Zhuzhahe, Zhiligou and Mengguogou. Specially, there are more than 300 villagers living near the alluvial fan of Zhuzhahe catchment.

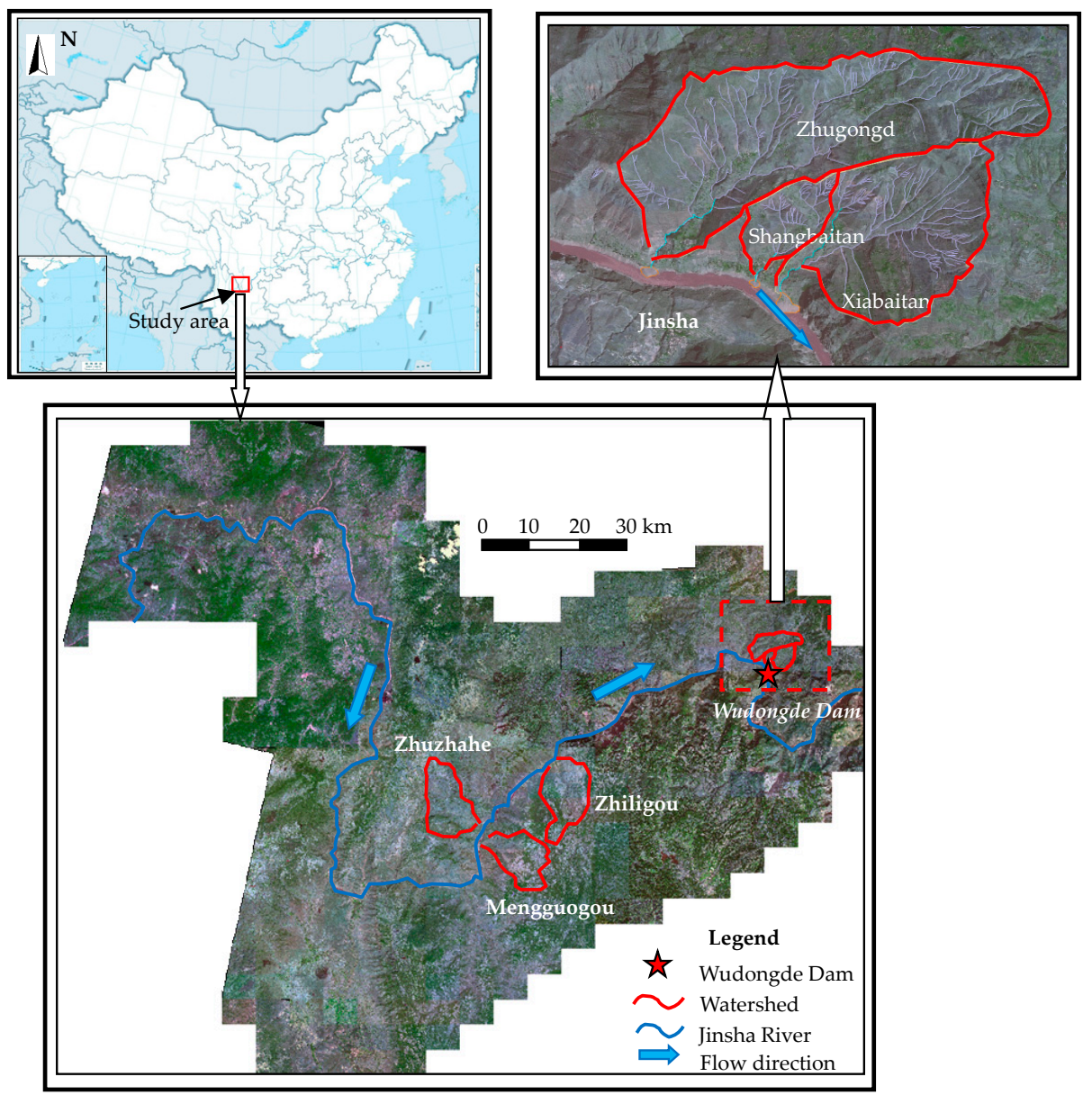

Figure 1. Location of the study area in the region of Wudongde Dam.

In the case that the discharge of a future debris flow event would block the river, it would cause a huge mass of water to surge quickly, thereby hindering construction processes in nearby hydropower stations and threatening the lives of people living downstream of these stations [41]. It can be seen in Figure 3 that the debris flow alluvial has a great impact on the villages and farmlands. Meanwhile, the alluvial fan also narrows the width of the Jinsha River [21,42-44]. If the river width becomes narrow, the river flow velocity will become fast. Consequently, the power of the river will become stronger, which makes the incision of the riverbed.

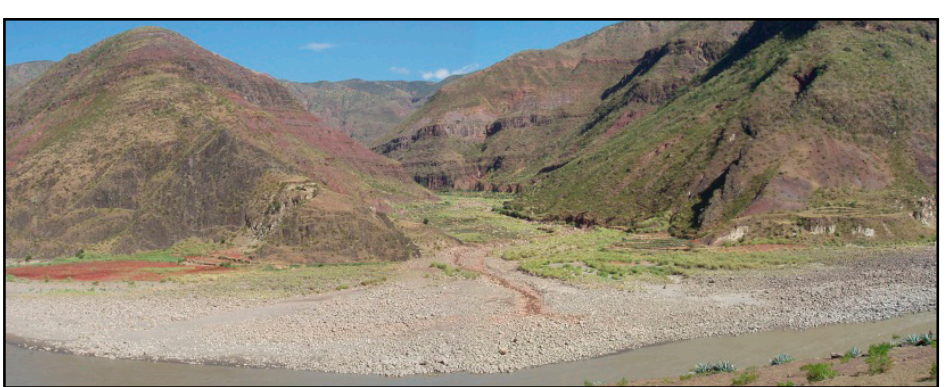

(a)

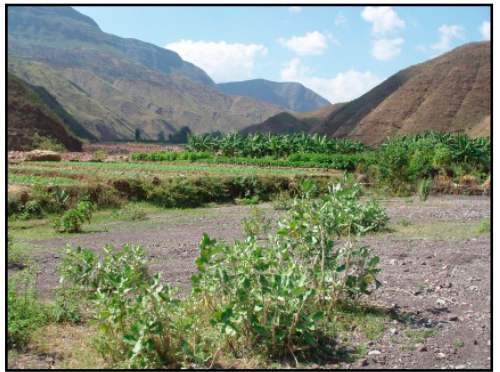

(b)

Figure 2. Field investigation: (a) Mengguogou alluvial fan; and (b) farmlands in Zhuzhahe. 


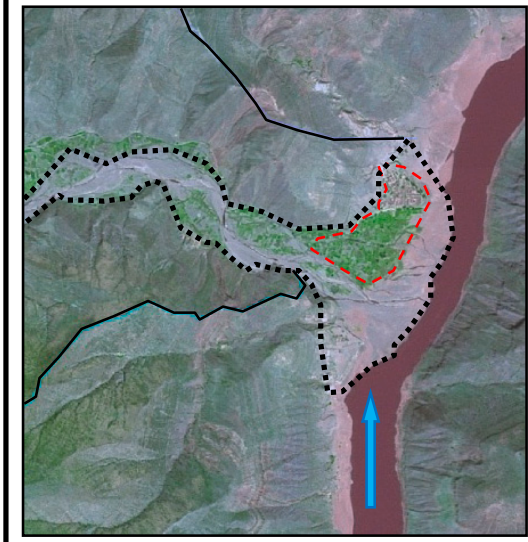

(a)

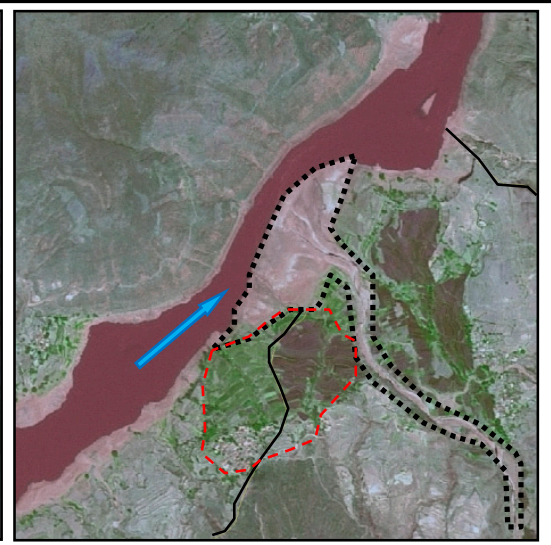

(b)

Figure 3. Alluvial fans of the gullies: (a) Zhuzhahe; and (b) Zhiligou.

\section{Data Acquisition}

The Jiangjia gully (JJG) is located in Yunnan Province of China, which is located in the same area as the Wudongde Dam site. They have similar geological and environmental conditions. Detailed information can be found in Chen [45] and Cui [46]. Dozens of debris flow occur in the JJG every year. Observation station was built there in 1961. Many measured data obtained there were used for researches. This study selects 50 groups of measured velocity data in the JJG to present the GSA-RBF approach. Then, this approach is applied to the six gullies in the study area. Because different variables have different value ranges and dimensions, the variables should be normalized so that when the function value is close to 0 or 1 , its changing rate is very slow. In order to improve the training speed, this paper normalizes the data to $(0.1,0.9)$ based on the following equation:

$$
N=0.8\left(X-X_{\min }\right) /\left(X_{\max }-X_{\min }\right)+0.1
$$

where $N$ is the normalized data, $X$ is the input variable index value, and $X_{\max }$ and $X_{\min }$ are the maximum and minimum index values, respectively.

In the JJG, average debris flow velocity is measured by timing the surge front passing through two fixed cross sections. In this study, a total of 50 groups measured data were investigated in the JJG. Forty groups $(80 \%)$ of the measured data were randomly used as training data. They were used for building prediction approach. The other ten groups $(20 \%)$ of data were used as testing data (Table 1$)$.

Table 1. Values of debris flow velocity and impact variables in the Jiangjia gully.

\begin{tabular}{cccccccccc}
\hline$y$ & $\boldsymbol{x}_{\mathbf{1}}$ & $\boldsymbol{x}_{\mathbf{2}}$ & $\boldsymbol{x}_{\mathbf{3}}$ & $\boldsymbol{x}_{\mathbf{4}}$ & $\boldsymbol{y}$ & $\boldsymbol{x}_{\mathbf{1}}$ & $\boldsymbol{x}_{\mathbf{2}}$ & $\boldsymbol{x}_{\mathbf{3}}$ & $\boldsymbol{x}_{\mathbf{4}}$ \\
\hline 8.8 & 150 & 6.3 & 2200 & 1.1 & 3.7 & 40 & 6.3 & 2020 & 0.1 \\
7.8 & 140 & 6.3 & 1950 & 0.6 & 4.1 & 70 & 5.8 & 1800 & 0.2 \\
3.8 & 40 & 6.3 & 1850 & 0.1 & 3.5 & 50 & 5.8 & 1760 & 0.2 \\
6.9 & 202 & 5.5 & 2270 & 1.7 & 8.2 & 130 & 6.6 & 2200 & 0.7 \\
7.5 & 168 & 5.5 & 2280 & 1.6 & 4.8 & 93 & 5.8 & 1920 & 0.3 \\
8.9 & 175 & 6.3 & 2080 & 0.8 & 9.2 & 372 & 6.6 & 2210 & 1.2 \\
7.4 & 200 & 6.3 & 2210 & 1.7 & 9.6 & 220 & 6.6 & 2290 & 1.5 \\
7.3 & 90 & 6.3 & 2210 & 1 & 5.8 & 107 & 5.5 & 2290 & 1.2 \\
6.6 & 70 & 6.3 & 2190 & 1.2 & 3.9 & 55 & 5.8 & 2070 & 0.8 \\
9.4 & 210 & 6.6 & 2210 & 1.2 & 5.6 & 70 & 5.5 & 1920 & 0.3 \\
4 & 40 & 6.3 & 2040 & 0.3 & 3.9 & 60 & 5.5 & 1830 & 0.1 \\
7.4 & 145 & 5.5 & 2250 & 1.1 & 6.9 & 122 & 5.5 & 2210 & 1 \\
5.8 & 103 & 5.5 & 2210 & 0.8 & 9.6 & 275 & 6.6 & 2210 & 1.6 \\
4.7 & 60 & 5.5 & 1970 & 0.5 & 5 & 65 & 5.5 & 2240 & 1.1 \\
7.7 & 161 & 5.5 & 2250 & 1 & 3.7 & 55 & 5.8 & 1800 & 0.1 \\
7.7 & 177 & 5.5 & 2240 & 1.1 & 8.1 & 160 & 6.6 & 2220 & 1.2 \\
7.9 & 200 & 6.3 & 2250 & 1.4 & 6.6 & 226 & 5.5 & 2130 & 1.1 \\
\hline
\end{tabular}


Table 1. Cont.

\begin{tabular}{cccccccccc}
\hline$y$ & $x_{1}$ & $x_{2}$ & $x_{3}$ & $x_{4}$ & $y$ & $x_{1}$ & $x_{2}$ & $x_{3}$ & $x_{4}$ \\
\hline 8.4 & 210 & 6.6 & 2200 & 0.8 & 7.4 & 55 & 6.3 & 2250 & 0.9 \\
9.3 & 210 & 6.3 & 2290 & 1 & 7.5 & 170 & 6.6 & 2190 & 1.1 \\
3.6 & 58 & 5.8 & 1690 & 0.2 & 6.4 & 109 & 5.5 & 2250 & 1.1 \\
10 & 95 & 6.3 & 2160 & 0.6 & 9.3 & 210 & 6.3 & 2210 & 1.1 \\
7.6 & 125 & 6.3 & 2100 & 0.6 & 6.9 & 250 & 5.5 & 2220 & 0.9 \\
7.6 & 11 & 6.3 & 2070 & 0.7 & 6 & 120 & 5.5 & 2200 & 0.8 \\
7.6 & 100 & 6.3 & 2190 & 0.9 & 4.9 & 60 & 5.5 & 1990 & 0.6 \\
8.5 & 200 & 6.3 & 2300 & 1.5 & 3.6 & 52 & 5.8 & 1700 & 0.1 \\
\hline
\end{tabular}

Notes: $y$ is field observed average velocity of debris flows $(\mathrm{m} / \mathrm{s}) ; x_{1}$ is flow depth $(\mathrm{cm}) ; x_{2}$ is the gradient of channel $(\%) ; x_{3}$ is the density of debris flow $\left(\mathrm{kg} \cdot \mathrm{m}^{-3}\right)$; and $x_{4}$ is the average grain size $(\mathrm{cm})$.

The six gullies' data were mainly obtained through field investigation, remote sensing and grain size analysis. The flow depth data were obtained in the field by measuring the ancient debris flow mud depth. After debris flow outbreak, the viscous fluid will leave scratches or mud marks in the ditch sidewall. The mud marks are regarded as flow depth of debris flow. There are several evidences that help us to determine the flow depth, such as the deposition in the rock crevices, the scratches and mud trace on the ditch sidewall, and drifts stranded in branches and rock and riverside. Figure 4 shows the mud marks in the study area, which helps us to determine the ancient debris flow depth. Through remote sensing and satellite images, we could obtain the DEMs of the six gullies. The gradient of channel is defined as the ratio of elevation difference and the horizontal distance in debris flow gully. It was obtained from the DEMs through the Geographic Information System (GIS) software.

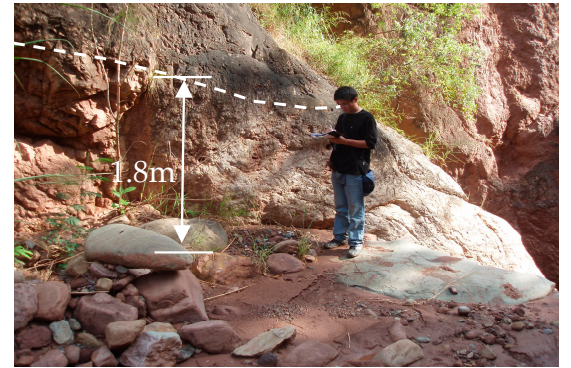

(a)

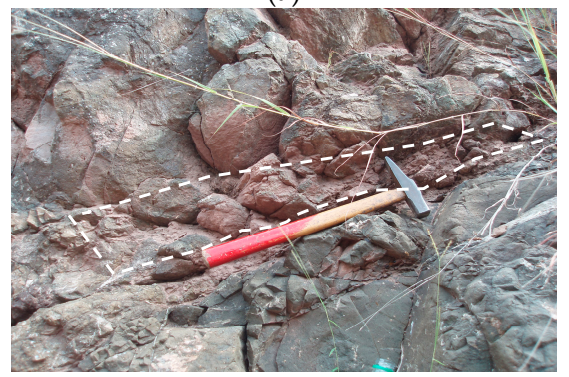

(c)

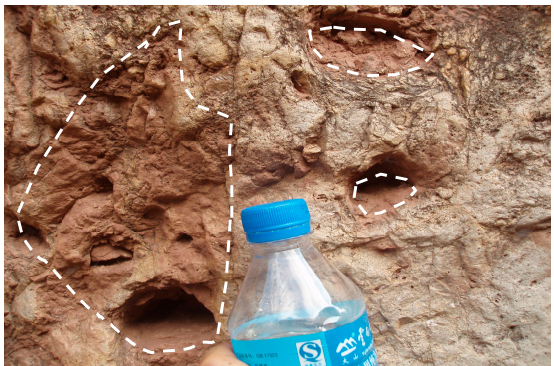

(b)

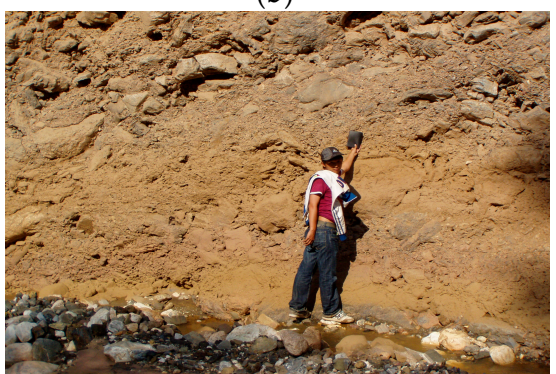

(d)

Figure 4. Field survey: (a) debris flow scouring in the downstream of flowing area in Zhugongdi; (b) debris flow mud marks in Zhugongdi; (c) rock crevices filled with mud in Xiabaitan; and (d) debris flow scouring in the downstream of flowing area in Zhiligou.

The grain size analysis was operated by in situ sieving analysis and the laboratory method. We took two parallel samples on the thickest profile from alluvial fans. One is on the top of the profile, and the other is from the bottom. A set of sieves with sizes of 2, 5, 10, 20, 40, and $60 \mathrm{~mm}$ were used to sieve the samples in the field (Figure 5). However, the grains size smaller than $2 \mathrm{~mm}$ could not be tested in situ. Therefore, grains size smaller than $2 \mathrm{~mm}$ samples were analyzed using hydrometer method in laboratory. Grains size larger than $60 \mathrm{~mm}$ could not be conducted through sieving procedures, thus the image analysis described by Tiraniti et al. [47] was used for determining 
the distribution of large grains. We selected suitable scaled photos and estimated the proportions of the grains lager than $60 \mathrm{~mm}$. Image analyzing might not be very accurate, but it provides a more feasible method than sieving analysis. The debris flow density was obtained by sieving experiment. After the sieving test, the sieved solid was put into a specified container in turn according to the grain size, from largest to smallest. Then, we shook the container and pressed the samples to make the grains fully mixed. Then, we obtained the dry density of the samples by weighs and volume of the samples. The density depends mainly on the triggering discharge (rainfall), on the channel slope and on the transport capacity (entrainment rate) that determines the sediment concentration. Therefore no post debris flow density analysis based on sieving experiment is reliable, only in situ measurements promptly after the propagation and deposition are meaningful. The debris flow is composed of water and solid materials. The dry density cannot reflect the debris flow density, so we poured water into the containers. When the volume of water is two-third of the solid materials, we could obtain the first density. By continuing to add water into the container, we could get the second density when the volume of water is the same as the solid materials. In vicious debris flow, the sediment concentrations are often in excess of $40 \%$ in volume. As the field conditions are relatively simple, we used the second density, whose sediment concentration is about $50 \%$ in volume, as the density of debris flow $\left(x_{3}\right)$ data in this study. The influencing variables data are shown in Table 2. Figure 6 shows how the density is obtained in the field.

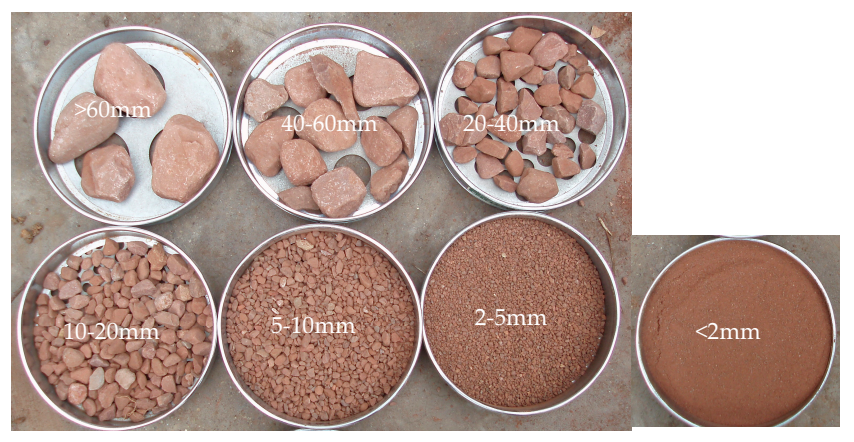

Figure 5. Sieving analysis in situ.

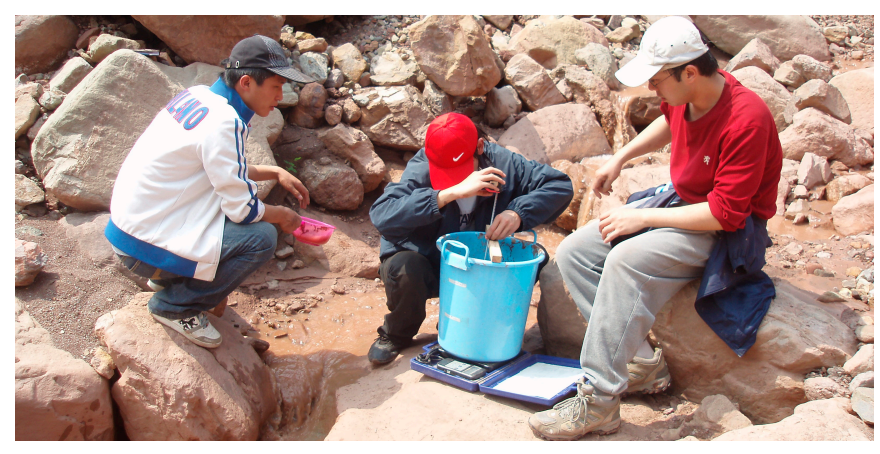

Figure 6. Obtaining the density in the field.

Table 2. Variables data of six gullies.

\begin{tabular}{ccccc}
\hline Gully & $\boldsymbol{x}_{\mathbf{1}} \mathbf{( \mathbf { c m } )}$ & $\boldsymbol{x}_{\mathbf{2}} \mathbf{( \% )}$ & $\boldsymbol{x}_{\mathbf{3}} \mathbf{( \mathbf { k g } \cdot \mathbf { m } ^ { - \mathbf { 3 } } )}$ & $\boldsymbol{x}_{\mathbf{4}} \mathbf{( \mathbf { c m } )}$ \\
\hline Xiabaitan & 200 & 40.7 & 2250 & 3.23 \\
Shangbaitan & 150 & 35.8 & 2110 & 3.08 \\
Zhugongdi & 180 & 41.8 & 2040 & 2.97 \\
Zhuzhahe & 180 & 5.0 & 2120 & 2.15 \\
Zhiligou & 170 & 10.2 & 2320 & 3.23 \\
Mengguogou & 180 & 5.6 & 2100 & 3.06 \\
\hline
\end{tabular}




\section{Methodology}

\subsection{Radial Basis Function Neural Network}

Many processing elements called neurons work together in this system to solve problems. The artificial neurons can be produced by computer program. An artificial neural network (ANN) is created through the interconnected artificial neurons. This artificial neural network is capable of learning and can be trained via a proper learning algorithm. There are different types of artificial neural networks. One type of ANN is the radial basis function (RBF) neural network which uses radial basis functions as activation functions. Radial basis function (RBF) neural network is a feed-forward network. Its structure is similar to multilayer forward network. The RBF neural network has three layers: an input layer, a hidden layer with nonlinear RBF activation functions and a linear output layer. The structure of the RBF neural network is shown in Figure 7. The input layer is composed of a signal source node. The output layer in the higher dimension space can realize the linear weighted combination. The most used basis function is Gauss function. For any input vector $X \in R^{n}$ :

$$
R_{i}(x)=e^{\left(\frac{-\left\|X-C_{i}\right\|^{2}}{2 \alpha_{i}^{2}}\right)} i=1,2, \ldots, p
$$

where $R_{i}(x)$ is output of the $i$ th hidden neuron. $X$ is the $n$-dimension input vector. $C_{i}$ is the center vector of the $i$ th neuron. $\alpha_{i}$ is the basis width vector that can usually be determined experimentally.

RBF neural network learning process comprises unsupervised learning and supervised learning. The unsupervised learning stage employs $K$-means clustering method to cluster the training samples. After finding the cluster center $C_{i}$ and $\alpha_{i}$, it conducts the supervised learning. When the $C_{i}$ and $\alpha_{i}$ are determined, RBF neural network becomes a linear function from input to output. The steps are as follows.

Step 1. Initialize the weights randomly

Step 2. Calculate the output vector $Y$ by the equation:

$$
y_{i}=\sum_{i=1}^{p} W_{i} R_{i}
$$

where $W_{i}$ is the weight of the $i$ th hidden neuron to the output node.

Step 3. Calculate the error $\varepsilon_{i}$ for each neuron in the output by the equation:

$$
\varepsilon_{i}=y_{i}-y_{i}^{\prime} i=1,2, \ldots, p
$$

where $y_{i}^{\prime}$ is the desired output of the $i$ th neuron in the output layer.

Step 4. Based on the least squares method, determine the weights between the hidden neurons and the output nodes:

$$
W=e^{\left(\frac{p}{c_{\max }^{2}}\left\|X-C_{i}\right\|^{2}\right)} i=1,2, \ldots, p
$$

where $c_{\max }$ is the maximum distance between the selected centers.

Step 5. Update the weights until the error meets the requirement:

$$
W_{i j}^{\prime}=W_{i j}+\mu \varepsilon_{i} R_{j} i=1,2, \ldots, m, j=1,2, \ldots, p
$$

where $W^{\prime}{ }_{i j}$ is the updated weight and $\mu$ is learning rate. When the network clustering center $C_{i}$ and weight $W_{i}$ are determined, we can conduct the predictions with the training model. 


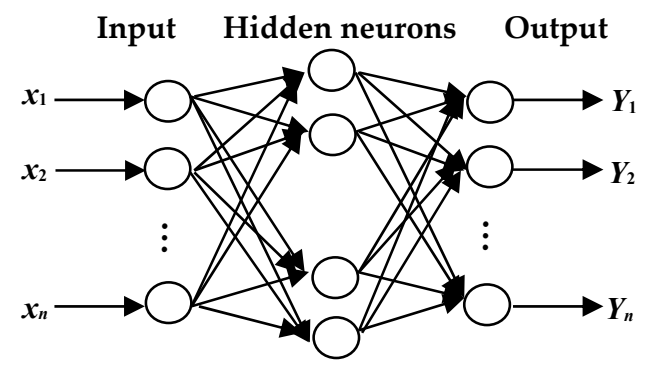

Figure 7. The general structure of RBF neural network.

\subsection{The Gravitational Search Algorithm}

Gravitational search algorithm (GSA) was proposed by Esmat Rashedi [48], which is a new intelligent algorithm. GSA is a heuristic clustering algorithm, similar to genetic algorithm, particle swarm optimization algorithm, ant colony optimization algorithm and simulated annealing algorithm. It makes use of the gravitational force between particles in each group to guide the global population search. The GSA can effectively avoid falling into local optimum to a solution.

GSA is inspired by the physical laws. In GSA, each individual contains four attributes: position, inertial mass, active gravitational mass and passive gravitational mass. The position of individual is the solution of the problem. To describe the GSA, consider a system with $N$ agents masses:

$$
X_{i}=\left(x_{i}^{1}, \ldots, x_{i}^{d}, \ldots, x_{i}^{n}\right), i=1,2, \ldots, n
$$

where $x_{i}^{d}$ means the position of $i$ th in $d$ th space. In the process of the $i$ th iteration, the force of individual $j$ act on $i$ is defined as

$$
\begin{gathered}
F_{i j}^{d}(t)=G(t) \frac{M_{p i}(t) M_{a j}(t)}{R_{i j}(t)+\varepsilon}\left(x_{j}^{d}(t)-x_{i}^{d}(t)\right) \\
R_{i j}(t)=\left\|X_{i}(t), X_{j}(t)\right\|_{2}
\end{gathered}
$$

where $G(t)$ is gravitational constant under the time $t, M_{a j}(t)$ is active gravitational mass of individual $j, M_{p i}(t)$ is positive gravitational mass of individual $i, \varepsilon$ is a very small constant, and $R_{i j}(t)$ means the Euclidean distance between the individual $i$ and individual $j$.

Individual $i$ forced by others in the $d$-dimension can be expressed as:

$$
F_{i}^{d}(t)=\sum_{j=1, j \neq i}^{N} \operatorname{rand}_{j} F_{i j}^{d}(t)
$$

where $\mathrm{rand}_{j}$ is a random number within the range of $[0,1]$, which increases the randomness of the algorithm.

The acceleration function of individual $i$ in the $d$-dimension can be calculated by the following equation:

$$
a_{i}^{d}(t)=\frac{F_{i}^{d}(t)}{M_{i i}(t)}
$$

where $M_{i i}(t)$ means the inertial mass of the individual $i$. The position of individual $i$ is updated by Equations (12) and (13).

$$
\begin{gathered}
v_{i}^{d}(t+1)=\operatorname{rand}_{i} \times v_{i}^{d}(t)+a_{i}^{d}(t) \\
x_{i}^{d}(t+1)=x_{i}^{d}(t)+v_{i}^{d}(t+1)
\end{gathered}
$$

where $v_{i}{ }^{d}(t)$ is the speed of $i$ in the $d$-dimension, $x_{i}{ }^{d}(t)$ is the position of $i$ in the $d$-dimension, and rand ${ }_{i}$ is a real number within $[0,1]$, which can enhance the ability of random search algorithm. 
$G_{0}$ is the initial value of gravitational constant $G$, with the increase of iteration times, $G$ will gradually decrease to control the accuracy of the search. $G$ is a function of $G_{0}$ and $t$ :

$$
G(t)=G_{0} e^{-\alpha \frac{t}{\operatorname{maxiter}}}
$$

where $G_{0}$ and $\alpha$ are constant, max iter is the maximum number of iterations.

The gravitational mass and inertial mass can be calculated by the fitness function. Assuming that the gravitational mass and inertial mass are equal:

$$
\begin{gathered}
M_{a i}=M_{p i}=M_{i i}=M_{i}, i=1,2, \ldots, N \\
m_{i}(t)=\frac{\operatorname{fit}(t)-\operatorname{worst}(t)}{\operatorname{best}(t)-\operatorname{worst}(t)} \\
M_{i}=\frac{m_{i}(t)}{\sum_{j=1}^{N} m_{j}(t)}
\end{gathered}
$$

where fit $i_{i}(t)$ means the fitness value of $i$ at $t$, and best $(t)$ and worst $(t)$ are defined, respectively, as Equations (18) and (19):

$$
\begin{aligned}
\operatorname{best}(t) & =\min _{j \in\{1,2, \ldots, N\}} \mathrm{fit}_{j}(t) \\
\operatorname{worst}(t) & =\max _{j \in\{1,2, \ldots, N\}} \mathrm{fit}_{j}(t)
\end{aligned}
$$

\subsection{The Proposed GSA-RBF Method}

In this study, we proposed an approach of using the gravitational search algorithm to optimize the parameters of RBF neural network. By the proposed approach, we can obtain the optimal solution.

Assuming that the scale of the particles swarm is $n$. The position of $i$ individual is represented by $M$-dimension vector $X_{i}$. The position of particles swarm is presented by matrix $\boldsymbol{X}_{n} \times M . f(x)$ is the minimized objective function, the optimized objective function of $i$ th individual is:

$$
f\left(X_{i}(t)\right)=\frac{1}{L} \sum_{l=1}^{L} \sum_{m=1}^{M}\left(y_{l m}(t)-y_{l m}^{\prime}(t)\right)^{2}
$$

where $L$ is the number of training data, $M$ is the number of output neurons, $y^{\prime}{ }_{l m}(t)$ is expected output value, and $y_{l m}(t)$ is the actual output value.

The specific steps of building GAS-RBF approach using 50 groups of measured velocity data in the JJGB is shown in Figure 8.

\subsection{The Modified Dongchuan Empirical Equation}

The widely used equation in China, the modified Dongchuan empirical equation [29] (MDEE), was used for calculating the six debris flow velocities. It can be used to validate the proposed approach. The modified Dongchuan empirical equation for calculating viscous debris flow velocity is as follows:

$$
V=K H^{\frac{2}{3}} J^{\frac{1}{5}}
$$

where $V$ is debris flow velocity, $K$ is coefficient of viscous debris flow velocity, $H$ is the flow depth, and $J$ is channel gradient of gully. 


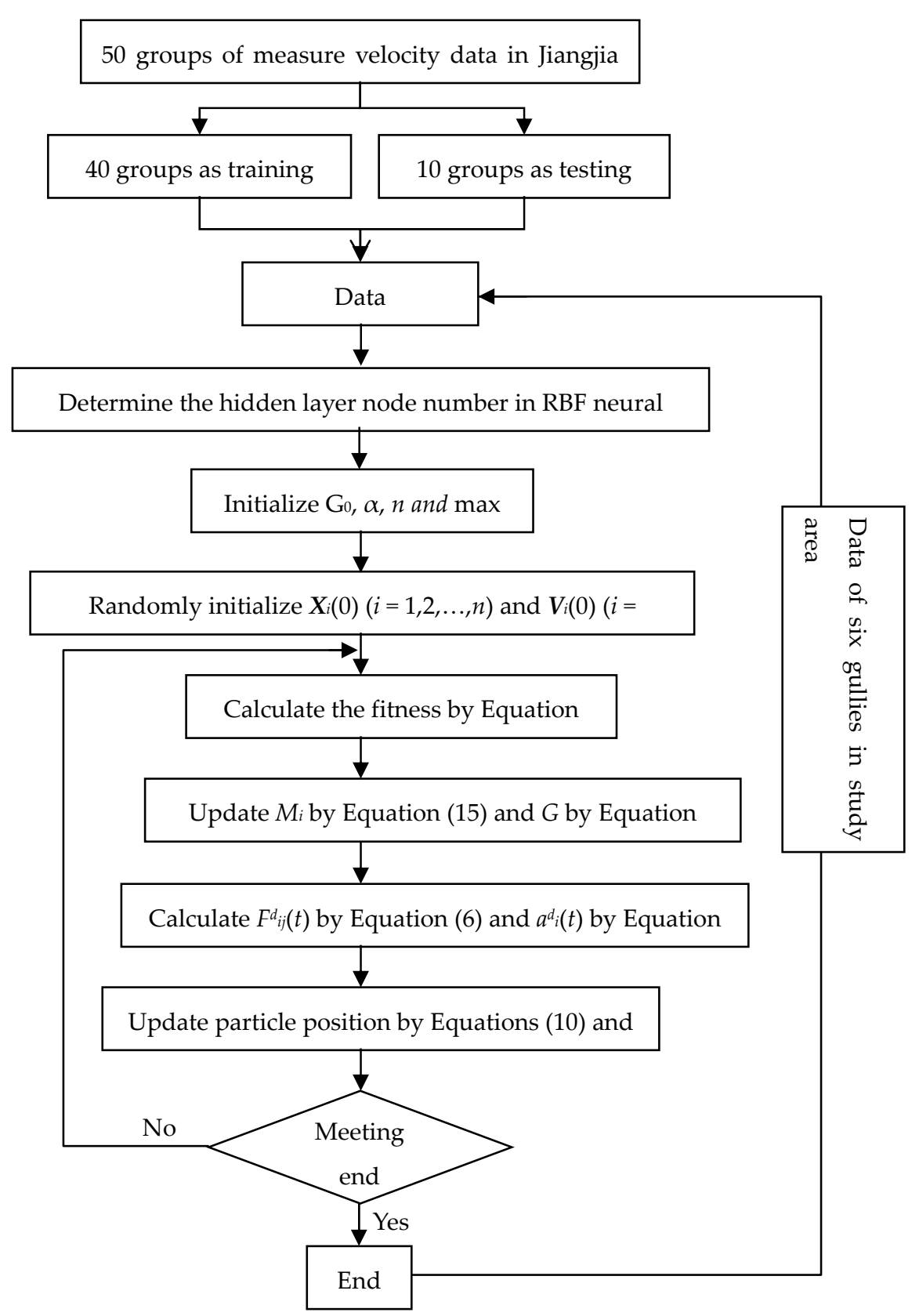

Figure 8. Steps of building the proposed GSA-RBF approach.

\section{Results and Discussion}

In Table 3, the results of 10 randomly selected testing data using RBF, MDEE and the proposed GSA-RBF methods are presented. The measure values of the 10 testing data are obtained by field measurements. The average relative errors using RBF, MDEE and GSA-RBF are $14.6 \%, 5.4 \%$, and $3.7 \%$, respectively. The maximum relative errors using RBF, MDEE and GSA-RBF are $30.3 \%, 10.3 \%$ and $7.8 \%$, respectively. We fit the data with straight lines and compute their correlation degree: (i) Figure 9a shows a $x-y$ plots of the measured velocity versus the RBF velocity, whose $R^{2}$ value is 0.836 ; (ii) Figure $9 \mathrm{~b}$ shows the measured velocity versus the MDEE velocity, whose $R^{2}$ value is 0.942 ; and (iii) Figure 9c shows the measured velocity versus the GSA-RBF velocity, whose $R^{2}$ value is 0.968 . RBF performs the worst among the three methods. The MDEE results and the GSA-RBF results are almost the same, which are similar to the measured velocity. However, the GSA-RBF has the strongest correlation with the measured velocity. Thus, the GSA-RBF algorithm produced the highest quality 
solution in terms of predicting debris flow average velocity on the testing data in the JJG. The GSA-RBF is able to find a near optimal solution while RBF easily trap into local optima. The GSA improves the quality of solutions found by the RBF neural network. In this study, we used 40 groups of data as training data, while $\mathrm{Xu}$ et al. used 45 groups of data as training data. In addition, we selected ten groups as testing data. $\mathrm{Xu}$ et al. selected five groups as testing data, which were very different from what we selected. The average relative errors using the GSA-RBF method (3.7\%) and Xu and coworkers' method (1.3\%) were very close, and both were acceptable.

Table 3. The testing results of using RBF, MDEE and GSA-RBF.

\begin{tabular}{|c|c|c|c|c|c|c|}
\hline \multirow{2}{*}{$\begin{array}{l}\text { Measured Value } \\
(\mathrm{m} / \mathrm{s})\end{array}$} & \multicolumn{2}{|c|}{ RBF } & \multicolumn{2}{|c|}{ MDEE } & \multicolumn{2}{|c|}{ GSA-RBF } \\
\hline & Value $(\mathrm{m} / \mathrm{s})$ & Relative Error (\%) & Value (m/s) & Relative Error (\%) & Value $(\mathrm{m} / \mathrm{s})$ & Relative Error (\%) \\
\hline 4.8 & 6.1 & 27.1 & 5.0 & 3.6 & 5.0 & 4.2 \\
\hline 4.9 & 5.3 & 8.2 & 4.7 & 3.6 & 4.8 & 2.0 \\
\hline 4.7 & 5.3 & 12.8 & 4.7 & 0.5 & 4.7 & 0.0 \\
\hline 7.7 & 7.9 & 2.6 & 7.2 & 6.3 & 7.1 & 7.8 \\
\hline 7.7 & 8.1 & 5.2 & 7.4 & 3.3 & 7.2 & 6.5 \\
\hline 3.9 & 5.0 & 28.2 & 4.2 & 7.0 & 3.6 & 7.7 \\
\hline 3.9 & 4.9 & 25.6 & 4.2 & 9.0 & 4.1 & 5.1 \\
\hline 6.4 & 6.2 & 3.1 & 5.8 & 10.0 & 6.4 & 0.0 \\
\hline 3.7 & 3.8 & 2.7 & 3.7 & 0.2 & 3.8 & 2.7 \\
\hline 7.6 & 9.9 & 30.3 & 6.8 & 10.3 & 7.7 & 1.3 \\
\hline Average error & - & 14.6 & - & 5.4 & - & 3.7 \\
\hline Maximum error & - & 30.3 & - & 10.3 & - & 7.8 \\
\hline
\end{tabular}
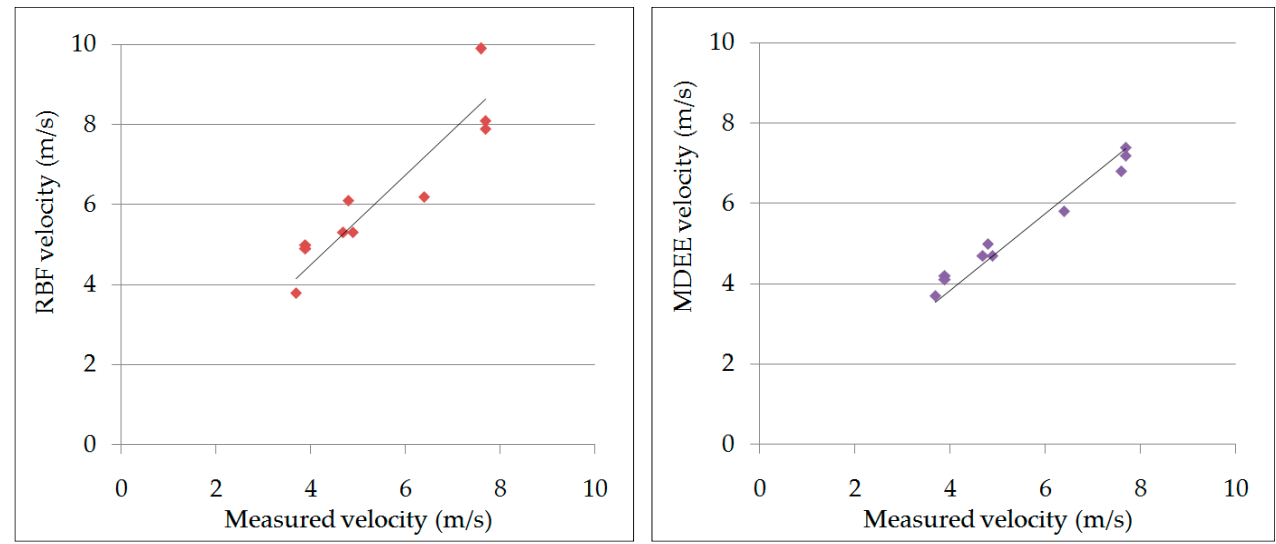

(a)

(b)

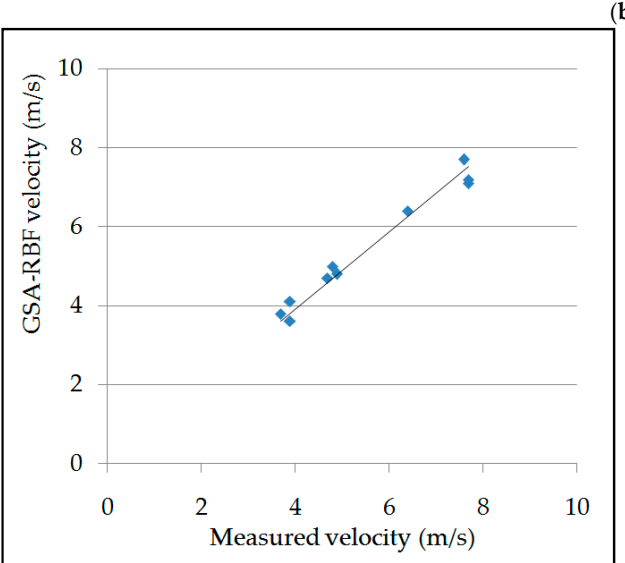

(c)

Figure 9. Fitness of 10 testing data in the JJG using three methods: (a) measured velocity versus the RBF velocity; (b) measured velocity versus the MDEE velocity; and (c) measured velocity versus the GSA-RBF velocity. 
Specifically, the geological and environmental conditions in Wudongde Dam site reservoir are similar to those of the JJG, and this study applies the GSA-RBF approach to predict the velocities of six debris flow gullies near the Wudongde Dam. The proposed GSA-RBF approach works well in predicting the JJG debris flow velocities. The six debris flow gullies in the study area are defined as viscous debris flow $[32,49,50]$. They are similar to the JJG debris flow. This contributes to the safety of the study area, helping protecting the buildings, farmland, villager lives and the environment. However, there is no measured velocity in the six gullies. In China, the MDEE [51] is especially used for calculating the debris flow velocity in the Dongchuan area. The study area is located in a similar area to the JJG in the Dongchuan area [32,50]. Thus, the MDEE is also suitable to calculate the debris flow velocities in the Wudongde dam area. Considering the research of the initiative condition of solid accretion of debris flow, the pulled particle analysis (PPA) was used as comparison. Huang has proven the PPA method to be a reliable method for predicting velocity in the study area. However, there still exists disadvantage in that case.

Figure 10 shows that the accuracy using PPA is not as good as GSA-RBF, especially for Zhuzhahe and Zhiligou. The MDEE is used as validation. The target grain size PPA method selected was the largest, which led the predicted velocity to be much higher. On the other hand, combining with the field investigation, the probability of occurring large scale debris flow was very low in the two gullies. Huang recommended using the MDEE to calculate Zhuzhahe and Zhiligou debris flow velocity. Meanwhile, debris flow can move very fast in steep channel, while it moves slower in low-gradient reaches. The channel gradient of Zhuzhahe and Zhiligou are $5.0 \%$ and $10.2 \%$, respectively, which are much smaller than those of Xiabaitan, Shangbaitan and Zhugongdi. The velocities of Zhuzhahe and Zhiligou should not be high. However, the PPA results are nearly the same as the other three mentioned predicted debris flow velocities.

In contrast, the results using GSA-RBF are very similar to those using MDEE. The results of six gullies using GSA-RBF are 13.9, 11.5, 11.2, 4.5, 6.8 and $9.1 \mathrm{~m} / \mathrm{s}$, respectively. The MDEE results are $13.3,10.7,12.4,4.1,6.3$ and $8.7 \mathrm{~m} / \mathrm{s}$, respectively. The average relative error ranges between $4.5 \%$ and $9.8 \%$. Such minor error can be ignored because the debris flow velocity is not always the same during its propagation. It means that the proposed GSA-RBF approach can be well applied to predicting the velocities in the study area. Wang et al. found that principle component analysis and self-organizing map methodologies are good predictors of basin susceptibility to debris flows. They found that the susceptibility class of Xiabaitan, Shangbaitan, Zhugongdi and Mengguogou are moderate. The susceptibility class of Zhiligou is low, and the susceptibility class of Zhuzhahe is very low. The velocity can reflect the dangerous degree of debris flow. The results of our study match with the susceptibility class results of Wang et al.: moderate, Xiabaitan $(13.9 \mathrm{~m} / \mathrm{s})$, Shangbaitan $(11.5 \mathrm{~m} / \mathrm{s})$, Zhugongdi $(11.2 \mathrm{~m} / \mathrm{s})$ and Mengguogou $(9.1 \mathrm{~m} / \mathrm{s})$; low, Zhiligou $(6.8 \mathrm{~m} / \mathrm{s})$; and very low, Zhuzhahe $(4.5 \mathrm{~m} / \mathrm{s})$. In Xu and coworkers' work, the velocities of Xiabaitan, Shangbaitan and Zhugongdi predicted using BP neural network are 12.8, 11.3 and $13.0 \mathrm{~m} / \mathrm{s}$, respectively. The results using $\mathrm{Xu}$ and coworkers' method and the proposed GSA-RBF are very close. We cannot determine which method is better, but both methods verify the accuracy of the other method. In other words, the works of $\mathrm{Xu}$ et al. and Wang et al. have proven that the results using GSA-RBF are reliable.

The MDEE is a good method for predicting the debris flow average velocities of the JJG. However, it is only applicable to debris flow in the Dongchuan area. It is very important to find a method that can be applied to predicting debris flows in other areas. In a later study, we could consider more variables in predicting the debris flow velocity using GSA-RBF on the basis of measured data in other areas. Although the MDEE has already given excellent results, it is shown in Equation (21) that the debris flow velocity is only influenced by two variables: flow depths and channel gradient of gully. The debris flow velocity is mainly dominated grain size, slope angle, sediment concentration, etc. [18-24]. In this study, we took four variables into consideration using the GSA-RBF. Variables influencing debris flow velocity are various $[25,26]$. In Table 1 , debris flow velocity shows a positive correlation with each of the four independent variables $\left(x_{1}, x_{2}, x_{3}\right.$, and $\left.x_{4}\right)$, but these correlations are weak ( $\mathrm{R}^{2}$ values range 
between 0.54 and 0.27). According to the previous work [26], we would expect a negative correlation between debris flow velocity and grain size. The positive correlation in this data set is almost certainly because of that these speed values do not depend only on grain size but on several variables at the same time $\left(x_{1}, x_{2}, x_{3}\right.$ and $\left.x_{4}\right)$. Furthermore, a single value of grain size cannot be representative of the large grain size distribution that occurs in a debris flow. The $\mathrm{x}_{1}, \mathrm{x}_{2}, \mathrm{x}_{3}$ and $\mathrm{x}_{4}$ values provide an oversimplified depiction of real debris flows. Thus, considering more variables affecting debris flow velocity, the GSA-RBF is more appropriate to predict debris flow average velocity.

Meanwhile, in order to get more accurate influencing variable data, fieldwork and experiments should be improved. For example, the average grain size plays a great role in predicting the velocities, so researchers need to select proper deposits for experiments. It is necessary to get more accurate average grain size. The widely used Wolman pebble count method $[52,53]$ is described by various publications. This technique requires the observer to measure sizes of random particles using a gravelometer. In later studies, we could try different sieving method to get the grain size variable. In addition, the deposits may be ancient landslide deposits, which are not the source of debris flow. Researchers should distinguish what the deposits are. Finally, the new proposed approach only uses 40 groups of data. Even though the data were reliably measured data, the data were insufficient and the range of the velocities was not large enough. More measured data should be used to establish a better approach for predicting debris flow velocity.

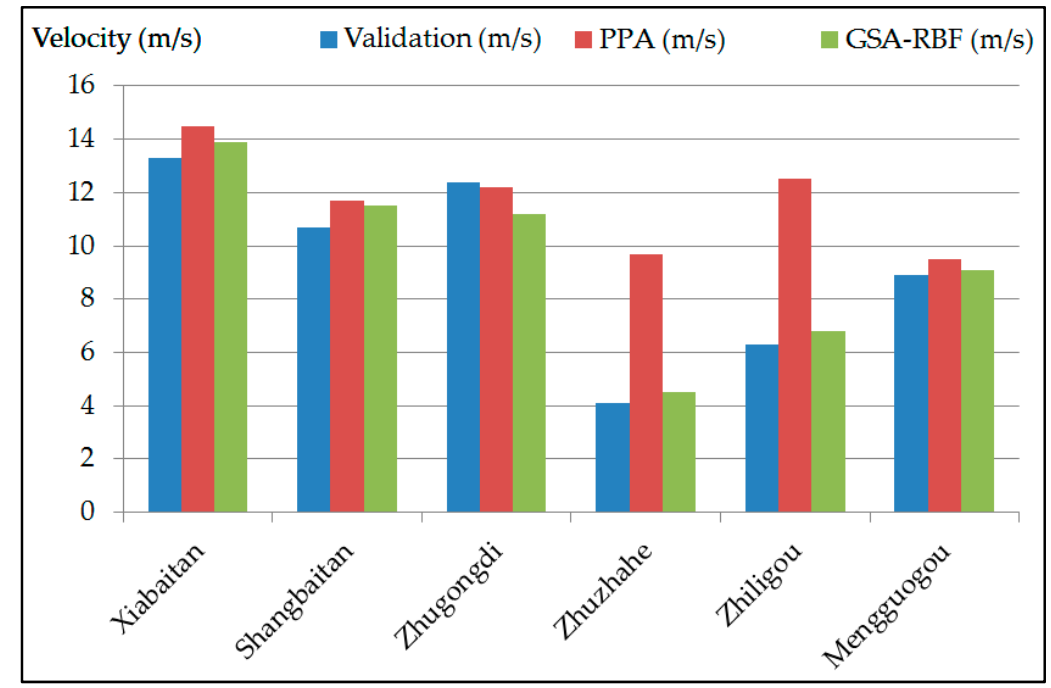

Figure 10. Debris flow average velocity results using PPA and GSA-RBF of six gullies.

\section{Conclusions}

This study selected four influencing variables including flow depth, gradient of the channel, debris flow density and average grain size. The measured velocity data in the Jiangia gully were used for building the GSA-RBF approach. Satellite images were introduced to select dangerous debris flow catchment.

The findings contribute to obtaining more accurate debris flow velocities of the six gullies in the study area. The findings are as follows: (i) the GSA-RBF predicted debris flow velocities are very close to the measured values, which performs better than those using RBF neural network alone; (ii) the GSA-RBF results and MDEE results are similar in the JJG debris flow velocities prediction, and GSA-RBF performs better; (iii) in the study area, the GSA-RBF results are validated as reliable; and (iv) we could consider more variables in predicting the debris flow velocity using GSA-RBF on the basis of measured data in other areas, which is more applicable. Because the accuracy of the GSA-RBF approach was high, both the numerical simulation and the empirical equation can be taken into consideration for constructing debris flow mitigation works. They could be complementary and 
verified for each other. The proposed approach is reliable to guide the development of the Wudongde Dam site area. The findings contribute to showing a good ability of proposed approach for predicting debris flow velocities. The results are helpful for decision makers to develop mitigation works to keep the Wudongde Dam working normally, and will also contribute to the sustainable environment development of the reservoir area.

Acknowledgments: This work was supported by the State Key Program of National Natural Science of China (Grant No. 41330636), and Natural Science Foundations of China (Grant No. 41602285). Thanks to anonymous reviewers for their valuable feedback on the manuscript. Thanks to Yicun Wang from the University of Kansas.

Author Contributions: Chen Cao contributed to data analysis and manuscript writing. Jianping Chen proposed the main structure of this study. Shengyuan Song, Lianjing Zheng and Yuanyuan Kong provided useful advice and revised the manuscript. All authors read and approved the final manuscript.

Conflicts of Interest: The authors declare no conflict of interest.

\section{References}

1. Cao, C.; Xu, P.; Chen, J.; Zheng, L.; Niu, C. Hazard assessment of debris-flow along the baicha river in heshigten banner, inner mongolia, china. Int. J. Environ. Res. Public Health 2016, 14, 30. [CrossRef] [PubMed]

2. Tang, C.; Zhu, J.; Li, W.L.; Liang, J.T. Rainfall-Triggered debris flows following the wenchuan earthquake. B Eng. Geol. Environ. 2009, 68, 187-194. [CrossRef]

3. Cui, P.; Zhu, Y.-Y.; Han, Y.-S.; Chen, X.-Q.; Zhuang, J.-Q. The 12 may wenchuan earthquake-induced landslide lakes: Distribution and preliminary risk evaluation. Landslides 2009, 6, 209-223. [CrossRef]

4. Cui, P.; Chen, X.Q.; Zhu, Y.Y.; Su, F.H.; Wei, F.Q.; Han, Y.S.; Liu, H.J.; Zhuang, J.Q. The wenchuan earthquake (May 12, 2008), sichuan province, china, and resulting geohazards. Nat. Hazards 2011, 56, 19-36. [CrossRef]

5. Hu, K.H.; Wei, F.Q.; Li, Y. Real-Time measurement and preliminary analysis of debris-flow impact force at jiangjia ravine, china. Earth Surf. Proc. Land 2011, 36, 1268-1278. [CrossRef]

6. Li, Y.; Liu, J.J.; Hu, K.H.; Su, P.C. Probability distribution of measured debris-flow velocity in jiangjia gully, yunnan province, china. Nat. Hazards 2012, 60, 689-701.

7. Cascini, L.; Cuomo, S.; Pastor, M. Inception of debris avalanches: Remarks on geomechanical modelling. Landslides 2013, 10, 701-711. [CrossRef]

8. Bugnion, L.; McArdell, B.W.; Bartelt, P.; Wendeler, C. Measurements of hillslope debris flow impact pressure on obstacles. Landslides 2012, 9, 179-187. [CrossRef]

9. Scheidl, C.; Chiari, M.; Kaitna, R.; Mullegger, M.; Krawtschuk, A.; Zimmermann, T.; Proske, D. Analysing debris-flow impact models, based on a small scale modelling approach. Surv. Geophys. 2013, 34, 121-140. [CrossRef]

10. Johnson, C.G.; Kokelaar, B.P.; Iverson, R.M.; Logan, M.; LaHusen, R.G.; Gray, J.M.N.T. Grain-Size segregation and levee formation in geophysical mass flows. J. Geophys. Res.-Earth 2012, 117. [CrossRef]

11. Murakawa, Y.; Hara, M.; Oguchi, H.; Hamate, Y.; Kuwano, H. Surface acoustic wave based sensors employing ionic liquid for hydrogen sulfide gas detection. Microsyst. Technol. 2013, 19, 1255-1259. [CrossRef]

12. Berti, M.; Genevois, R.; LaHusen, R.; Simoni, A.; Tecca, P.R. Debris flow monitoring in the acquabona watershed on the dolomites (Italian alps). Phys. Chem. Earth Part B 2000, 25, 707-715. [CrossRef]

13. Hurlimann, M.; Rickenmann, D.; Graf, C. Field and monitoring data of debris-flow events in the swiss alps. Can. Geotech. J. 2003, 40, 161-175. [CrossRef]

14. Uddin, M.S.; Inaba, H.; Itakura, Y.; Yoshida, Y.; Kasahara, M. Adaptive computer-based spatial-filtering method for more accurate estimation of the surface velocity of debris flow. Appl. Opt. 1999, 38, 6714-6721. [CrossRef] [PubMed]

15. Han, Z.; Chen, G.; Li, Y.; Xu, L.; Zheng, L.; Zhang, Y. A new approach for analyzing the velocity distribution of debris flows at typical cross-sections. Nat. Hazards 2014, 74, 2053-2070. [CrossRef]

16. Huang, Y.; Zhang, W.J.; Xu, Q.; Xie, P.; Hao, L. Run-Out analysis of flow-like landslides triggered by the ms 8.02008 wenchuan earthquake using smoothed particle hydrodynamics. Landslides 2012, 9, 275-283. [CrossRef]

17. Cascini, L.; Cuomo, S.; Pastor, M.; Sorbino, G.; Piciullo, L. Sph run-out modelling of channelised landslides of the flow type. Geomorphology 2014, 214, 502-513. [CrossRef] 
18. Armanini, A.; Capart, H.; Fraccarollo, L.; Larcher, M. Rheological stratification in experimental free-surface flows of granular-liquid mixtures. J. Fluid Mech. 2005, 532, 269-319. [CrossRef]

19. Hotta, N. Basal interstitial water pressure in laboratory debris flows over a rigid bed in an open channel. Natl. Hazards Earth Syst. Sci. 2012, 12, 2499-2505. [CrossRef]

20. Iverson, R.M.; Logan, M.; LaHusen, R.G.; Berti, M. The perfect debris flow? Aggregated results from 28 large-scale experiments. J. Geophys. Res.-Earth 2010, 115. [CrossRef]

21. Stancanelli, L.M.; Lanzoni, S.; Foti, E. Mutual interference of two debris flow deposits delivered in a downstream river reach. J. Mt. Sci.-Engl. 2014, 11, 1385-1395. [CrossRef]

22. Stancanelli, L.M.; Lanzoni, S.; Foti, E. Propagation and deposition of stony debris flows at channel confluences. Water Resour. Res. 2015, 51, 5100-5116. [CrossRef]

23. Takahashi, T. Debris Flow: Mechanics, Prediction and Countermeasures; CRC Press: Boca Raton, FL, USA, 2014.

24. Egashira, S.; MIYAMOTO, K.; Itoh, T. Constitutive equations of debris flow and their applicability. In Proceedings of the First International Conference Water Resources Engineering Division/ASCE, San Francisco, CA, USA, 2-6 September 2001; pp. 340-349.

25. Yang, H.J.; Wei, F.Q.; Hu, K.H. Mean velocity estimation of viscous debris flows. J. Earth Sci.-China 2014, 25, 771-778. [CrossRef]

26. Prochaska, A.B.; Santi, P.M.; Higgins, J.D. Relationships between size and velocity for particles within debris flows. Can. Geotech. J. 2008, 45, 1778-1783. [CrossRef]

27. Cagnoli, B.; Romano, G.P. Granular pressure at the base of dry flows of angular rock fragments as a function of grain size and flow volume: A relationship from laboratory experiments. J. Geophys. Res. Solid Earth 2012, 117. [CrossRef]

28. Julien, P.Y.; Paris, A. Mean velocity of mudflows and debris flows. J. Hydraul. Eng.-Asce 2010, 136, 676-679. [CrossRef]

29. Chen, G. Prevention and Control of Debris Flow; China Railway Press: Beijing, China, 1983.

30. Koch, T. Testing various constitutive equations for debris flow modelling. IAHS Publ.-Ser. Proc. Rep.-Intern Assoc. Hydrol. Sci. 1998, 248, 249-258.

31. Rickenmann, D. Empirical relationships for debris flows. Nat. Hazards 1999, 19, 47-77. [CrossRef]

32. Huang, R. Model Building and Calculation of the Debris Flow Rate in Dam Site of Wudongde Hydropower Station Based on Ppa. Ph.D. Dessertation, Jilin University, Changchun, China, 2011.

33. Riverol-Canizares, C.; Pilipovik, V. The use of radial basis function networks (rbfn) to predict critical water parameters in desalination plants. Expert Syst. Appl. 2010, 37, 7285-7287. [CrossRef]

34. Khodaveisi, J.; Dadfarnia, S.; Shabani, A.M.H.; Moghadam, M.R.; Hormozi-Nezhad, M.R. Artificial neural network assisted kinetic spectrophotometric technique for simultaneous determination of paracetamol and p-aminophenol in pharmaceutical samples using localized surface plasmon resonance band of silver nanoparticles. Spectrochim. Acta A 2015, 138, 474-480. [CrossRef] [PubMed]

35. Rasouli, Z.; Hassanzadeh, Z.; Ghavami, R. Application of a new version of ga-rbf neural network for simultaneous spectrophotometric determination of $\mathrm{zn}(\mathrm{ii}), \mathrm{fe}(\mathrm{ii}), \mathrm{co}(\mathrm{ii})$ and $\mathrm{cu}(\mathrm{ii})$ in real samples: An exploratory study of their complexation abilities toward mtb. Talanta 2016, 160, 86-98. [CrossRef] [PubMed]

36. Xu, L.; Wang, Q.; Chen, J. Forcast for average velocity of debris flow based on bp neural network. J. Jilin Univ. (Earth Sci. Ed.) 2013, 43, 186-191.

37. Wang, Q.; Kong, Y.Y.; Zhang, W.; Chen, J.P.; Xu, P.H.; Li, H.Z.; Xue, Y.G.; Yuan, X.Q.; Zhan, J.W.; Zhu, Y.J. Regional debris flow susceptibility analysis based on principal component analysis and self-organizing map: A case study in southwest china. Arab. J. Geosci. 2016, 9, 718. [CrossRef]

38. Poggio, T.; Girosi, F. Networks for approximation and learning. Proc. IEEE 1990, 78, 1481-1497. [CrossRef]

39. Yu, G.; Zhang, M.; Wang, G. Application and comparison of prediction models of support vector machines and back-propagation artificial neural network for debris flow average velocity. J. Hydraul. Eng. 2012, 43, 105-110.

40. Zhang, W.; Li, H.-Z.; Chen, J.-P.; Zhang, C.; Xu, L.-M.; Sang, W.-F. Comprehensive hazard assessment and protection of debris flows along jinsha river close to the wudongde dam site in china. Nat. Hazards 2011, 58, 459-477. [CrossRef]

41. Niu, C.; Wang, Q.; Chen, J.; Zhang, W.; Xu, L.; Wang, K. Hazard assessment of debris flows in the reservoir region of wudongde hydropower station in china. Sustainability 2015, 7, 15099-15118. [CrossRef] 
42. Dal Sasso, S.F.; Sole, A.; Pascale, S.; Sdao, F.; Pinzon, A.B.; Medina, V. Assessment methodology for the prediction of landslide dam hazard. Nat. Hazards Earth Syst. Sci. 2014, 14, 557-567. [CrossRef]

43. Dang, C.; Cui, P.; Cheng, Z.L. The formation and failure of debris flow-dams, background, key factors and model tests: Case studies from china. Environ. Geol. 2009, 57, 1901-1910. [CrossRef]

44. Ermini, L.; Casagli, N.; Farina, P. Landslide dams: Analysis of case histories and new perspectives from the application of remote sensing monitoring techniques to hazard and risk assessment. Ital. J. Eng. Geol. Environ. 2006, 1, 45-52.

45. Chen, J.; He, Y.; Wei, F. Debris flow erosion and deposition in jiangjia gully, yunnan, china. Environ. Geol. 2005, 48, 771-777. [CrossRef]

46. Cui, P.; Chen, X.; Waqng, Y.; Hu, K.; Li, Y. Jiangjia ravine debris flows in south-western china. In Debris-Flow Hazards and Related Phenomena; Springer: New York, NY, USA, 2005; pp. 565-594.

47. Tiranti, D.; Bonetto, S.; Mandrone, G. Quantitative basin characterisation to refine debris-flow triggering criteria and processes: An example from the italian western alps. Landslides 2008, 5, 45-57. [CrossRef]

48. Rashedi, E.; Nezamabadi-Pour, H.; Saryazdi, S. Gsa: A gravitational search algorithm. Inf. Sci. 2009, 179, 2232-2248. [CrossRef]

49. Xu, Y.N. Study on Flow Mechanism for Avalanche Soils and Scour and Silting Characteristics of Debris Flows. Ph.D. Dessertation, Institute of Water Conservancy and Hydroelectric Power Research, Beijing, China, 2001.

50. Liu, H.J.; Tang, C.; Cui, P. Gis-Based criticality zoning of debris flow in dongchuan district. Arid Land Geogr. 2005, 28, 445-449.

51. Specification of Geological Investigation for Debris Flow Stabilization dz/t 0220-2006; China Standard Press: Beijing, China, 2006.

52. Gregoretti, C.; Fontana, G.D. The triggering of debris flow due to channel-bed failure in some alpine headwater basins of the dolomites: Analyses of critical runoff. Hydrol. Process 2008, 22, 2248-2263. [CrossRef]

53. Wolman, M.G. A method of sampling coarse river-bed material. EOS Trans. Am. Geophys. Union 1954, 35, 951-956. [CrossRef]

(C) 2017 by the authors. Licensee MDPI, Basel, Switzerland. This article is an open access article distributed under the terms and conditions of the Creative Commons Attribution (CC BY) license (http:/ / creativecommons.org/licenses/by/4.0/). 